\title{
The Social History of Chronic STIs in Africa: Experiences from Cameroon
}

\author{
Ndi Loveline \\ Medical Anthropology, University of Yaoundé I, Cameroon
}

Copyright $(2018$ by authors, all rights reserved. Authors agree that this article remains permanently open access under the terms of the Creative Commons Attribution License 4.0 International License

\begin{abstract}
The emergence of chronic STIs in Africa has been a nightmare to medical and social scientists, making infected persons to show differences in clinical, therapeutic and social histories. Medical history shows that HIV/AIDS and HBV are the only chronic STIs in the world for now. This study presents social modifications within this community as persons infected with HIV/AIDS and HBV live their experiences in the context of Cameroon. It presents the traumatic experiences of these infections on the social lives of the infected and affected persons with their entourage. A contribution enriches the current literature on the social history of chronic STIs in Africa. A qualitative study that used the techniques of in-depth interviews, FGD and participant observations to collect data from a sample population of 108 persons living with HIV/AIDS, HIV/HBV co-infections, and HBV presenting therapeutic complications in the UTHY Cameroon. A FGD carried out with patients who are members of social networks and associations. Data analyzed and interpreted using a content analysis and the Social Dynamic Analysis of George Balandier. Persons living with HIV/AIDS have life-experiences that are quite traumatizing and differ from those with HBV. From the 80s till date, HIV patients lived a life of shame, fear, rejection and stigmatization causing a good number of suicidal deaths. This has caused many patients to die due to the refusal to seek medical care. Ignorance around HBV makes it stigma-free and more deadly as compare to the former. Coping strategies developed by these patients result in social modifications of this community.
\end{abstract}

Keywords Social History, Chronic STIs, Experiences, Cameroon

\section{Introduction}

HIV/AIDS have persisted in Africa for about three decades and is still a major health problem. This has been a great challenge to medical and social scientists who have been struggling to stabilize and reduce the number of deaths to no avail. Social scientists are concerned with models to explain the rapid deconstruction of the traditional lifestyles to for the construction of social relations that are neither African nor Western. This paper presents the gravity and pertinence of this public health issue in the edification of social modifications that have occurred in the individual and collective lifestyles. For more the past three decades, despite the enormous efforts put in place to arrest the devastating effects caused by this nightmare, memories have continued to be fresh as soon as the subject is mentioned. The social and emotional lifestyles of this community have been transformed due to coping strategies employed by people to accept their experiences with HIV/AIDS. The problem addressed in here is to know how these chronic infections have made a social history different from that made by other chronic illnesses that have existed. The formulation of the hypothesis; the health beliefs and social responses surrounding these infections are the cause of these social modifications in this community. The methodological approach used in this study is qualitative with descriptive case studies and narration of life-experiences.

The essence of this investigation is to identify the cause of the persistence of stigma in this community despite the various measures applied by the State to educated, counseled and informed the public on these infections. This might be because, these health issues have become more of social problems than biomedical issues due to the intimacy concerned. As such, a lot of therapeutic challenges are faced by patients, due to the rejection from their social entourage. The social modifications in individual and collective lifestyles in this community serve as an illustration to understand the level of psychological trauma caused by these infections. Knowledge on these social modifications demonstrates the part that health beliefs have played in contributing to the present social dynamics of this community. This literature would contribute to the advancement of the theoretical knowledge on chronic STIs and give practical models from an anthropological perspective in handling issues related to sexuality and 
chronic illnesses. It would help individuals of this community to acquire new social attitudes towards HIV/AIDS, HBV and chronic sexual infections in this community in general.

There exists an important gap in the previous human history on STIs. This is seen at the level of the interplay between health beliefs and social responses in traditional communities where social bonds are closely tied. In response to the reaction of the social entourage, new social bonds have been constructed as persons living with these infections try to cope with their new experiences as a result of their infection with these illnesses. This article shows the origin of new lifestyles in this community since the arrival of HIV/AIDS and HBV. The following paragraphs presents the overview of the study, methodology, historical events and life experiences of some cases, analyzes, discussions and conclusion.

\section{Overview of This Study}

This study presents the social modifications that have occurred in the individual and collective lifestyles of persons infected and affected persons with chronic STIs since it emergence in Cameroon. It describes the main events that have happened to change the emotional, psychological, social and cultural lives of infected persons and their entourages contributing to the deconstruction of the traditional African culture as far as social and emotional lives are concerned. In a context where the customs and traditions are lay much importance on marriage, sexuality and child bearing as a backbone of human existence. The arrival of HIV/AIDS has left many families in total disarray where fear and rejection stands at the center of any relationship, broking the bond of love and oneness. These infections have broken many families leaving orphans, widows, widowers, and single persons at random. The name HIV/AIDS has been taboo causing fear, shame and name-calling for infected and affected persons. The culture of care and assistance for the sick and the attributions of sick role to patients have died out. A lot of negative health beliefs and social responses have been built around these infections and those infected with them have to develop strategies in order to cope with the stigma and shame from the social entourage. There has been a rise in the culture of individualism, singleness, self-centeredness and no closeness due to these infections. HIV/AIDS have created the spirit of camouflage, singleness, and fear at the individual and collective levels within and without infected and affected persons.

\section{Background of This Study}

This study was carryout in the University Teaching Hospital Yaounde in Cameroon. This is a health institution and a referent center that receives patients from the four corners of this country due to its technical platform that is adapted to manage complicated cases of opportunistic infections from HIV. It is also one of the pioneer centers for the management of HBV and other and other types of hepatitis including severe health problems in Cameroon. Found in the political capital of this country, it is amongst the best health institutions with specialists in various domains who are mostly lecturers in the faculty of Medicine and biomedical sciences of the University of Yaounde. Most medical practitioners find it as a privilege to work and also to teach students who are on academic or professional internship in this institution. It is for this reason that, many patients scramble for their services. Cameroon is Africa in miniature, meaning that, it cultures are similar to those found in other parts of Africa. There is a universal culture that binds the African continent in general, although few disparities could be noted as you go deep in to culture specific characteristics. Although language is an important and powerful tool in culture differentiation, there is a general health belief about HIV/AIDS and HBV in Africa that makes it different from HIV/AIDS and HBV of the Western context. Meanwhile, Western cultures depend on the scientific denominations to identify diseases, the African cultures depend on local nomenclature that is not yet available for HIV/AIDS and HBV.

\section{Current State of Debate around Social History of Chronic STIs}

The nature of literature used in this study is mainly empirical literature gathered from previous studies carried out around this subject in social sciences. The main review approach is thematic and takes in to consideration themes that are directly related to sexually transmitted diseases and their social impacts. A summary of the existing literature shows that, the general strength of studies carried out on HIV/AIDS pandemic is geared towards the social impacts of the infection without stressing how these social impacts have contributed in the social modifications that have occurred in this community. A general limitations of the existing literature lies in the absence of the historical events that marks the evolution of this infection as infected and affected persons live their experiences.

The contribution of the current literature tries to fill the epistemological gap left by previous studies. Several studies in social sciences (Farmer 1996a, 1996b, 1997; Obbo 1993a, 1997; Reid 1998; Rose Hunt 1994; Fee and Fox 1988; Arnold 1993; Berridge and Strong 1993; Brandt 1993) have made attempts to look how sexually transmitted diseases intervene in human history and draw social meanings for the AIDS crisis. According to Oyekanmi, F (1994b), the issue of sexual permissiveness, moral decadence and laxity has been an age long affair, unfortunately, more pronounced in recent times. Premarital sexual intercourse is not only considered as a 
taboo, but the fear of not finding a suitable husband after being disvirgined. Young single ladies after yielding unnecessarily to sexual temptations in the older days, even though sexuality was a taboo, used to practice this in hidings. If any accident like sexual transmitted diseases (STDs) such as gonorrhoea or syphilis occurred, they could easily be treated with endogenous means without any scandal. In the cases of unexpected pregnancies, there were traditional measures to cover the messed. In some cultures, the young lady was forcefully sent to marriage and the pregnancy automatically belonged to the new husband. HIV therefore, is a disease that intends to unveil the hidden secret of people's sexual life that used to be practiced in this culture. Most victims do everything to preserve their social status by keeping their sero-status to themselves.

History reveals that HIV/AIDS was first discovered in the western countries in a socially devalued group of persons (homosexuals and intravenous drugs users). Recent studies (papers presented at an international symposium on the theme: Social Sciences and AIDS in Africa: review and prospect, held in Sali Portudal in Senegal in 1996) show that, the situation of HIV and HBV has been stabilized and is under good control in the Western countries whereas the situation is still alarming in Sub-Saharan Africa and Cameroon in particular where morbidity, mortality and a high prevalence rate prevail. Therapeutic challenges that result in the non-respect of the therapeutic norms is rampant. Notwithstanding, there seems to be a great disparity in the perceptions of HIV with respect to $\mathrm{HBV}$ which are infections that are similar in their pathogenic forms (viruses), modes of transmission (mainly through sex and blood contact) and chronicity. HIV is a worldwide issue, but recent studies on HIV have shown that, the present situation of HIV in the countries of the North is under good control. There are few cases of new infections, opportunistic infections, few deaths due to HIV and therapeutic challenges. In order to develop new behaviors and attitudes to cope with these new challenges, old social bonds have been broken to the construction of new types that deviates from the traditional African culture.

\section{Research Problem}

Chronic illnesses have always been a health burden to both the health care provider, the patient and his entourage. This situation is universal with therapeutic management consisting of psychosocial, medical, financial and material support. Chronic illnesses demands not only the management clinical symptoms, but a global care of the patient in his clinical, psychological, emotional and social aspects. But as concerns HIV/AIDS and HBV, other factors such as health beliefs have developed around them making them different from the case of other chronic infections. Negative perceptions resulting from health beliefs have resulted in the persistence of refractory attitudes amongst infected/affected persons and their entourage. Social responses caused by these health beliefs are the main factor concerned, making HIV/AIDS a taboo in Africa. These health beliefs have made HIV/AIDS more of a social issue than a biological issue. The social climate that has been created around this chronic STI is so strong and has negatively influenced therapeutic measures put in place.

This public health problem in Sub-Saharan Africa (SSA) has persisted for decades compared to Hepatitis B (HBV) which is still emerging. These viral infections have been a major cause of morbidity and mortality in Cameroon despite the relentless efforts of the government to arrest the situation. Meanwhile the incidence rate continues to be consistent and persistent, the average co-infection $\mathrm{HIV} / \mathrm{HBV}$ prevalence rate stands at $8-10 \%$ (WHO, 2014), the prevalence rate of HIV in the general population stands at $4.3 \%$ (EDS, 2011), the prevalence rate in pregnant women stands at 7.6\% (Plan PTME 2012). The challenges faced by the government at the level of prevention are due to the refusal or slowness of the population to change sexual attitudes. This slow rate of change in sexual attitudes and behaviors of infected, affected and non-infected persons is due to the disparities in perceptions and interpretations within the population and between infected persons. This has produced corresponding social responses that have influenced the therapeutic management (choice of treatment itineraries). Although, the financial cost for the medical follow-up of HBV outweighs that of HIV, many patient's care-takers seem to be motivated and curious to give care more to their relations who are suffering from hepatitis B infections than patients suffering from HIV/AIDS.

\section{Objectives of the Study}

The main objective of this study is to present the social history of chronic STIs in Cameroon. A recount and description of the various events mark the social modifications in this community since the emergence of the HIV/AIDS and Hepatitis B viruses in Cameroon and Sub-Saharan Africa in general. In order to archive this, two specific objectives have been developed. The first aims at describing the process of deconstruction of the traditional African setup as a result of the sensitizations made around HIV/AIDS that aimed to arrest the spread of this virus. The second aims at showing the reconstruction of new social bonded by those living with these infections as they develop coping strategies to adapt in the new social climate within and without. These objectives answer the main question that wanted to know; the social history of chronic STIs in Africa? With two specific questions developed as follows; why is the social history of HIV/AIDS in Cameroon different from the social history of other chronic diseases? What are the main social modifications that make up the social history of STIs Cameroon? 


\section{Research Methodology}

This study is limited in the context of Cameroon and it research methodology is qualitative. The study makes use of a qualitative approach in data collection, analyses and interpretation. While trying to identify the various social modifications that have occurred in this community as a result $\mathrm{HIV} / \mathrm{AIDS}$ and $\mathrm{HBV}$, the quality of data depended on the choice of informants or research participants. With the objective of generate new awareness and knowledge from the existing literature, as noted from research gaps. Motivation stemmed from the orientation in historical anthropology that permits the presentation of events in an evolutionary and chronological manner. The theoretical framework inspired from the Social Dynamic theory of George Balandier. The study has been designed to respect the inductive approach that moves from specific observations and case studies to a broader generalization.

The research participants were persons living with HIV/AIDS, HIV/AIDS /HBV co-infections, and HBV for above 05 years. Some of these persons were members of associations or social networks of person's livings with these infections. The research instruments used were; an observation guide, an interview guide and focus group discussion guide. A participant observation, in-depth interview, focus group discussion, and life history recount were used as techniques of data collection. The content analysis model was used to analyze the data. This method is reliable and trustworthy as rich data is collected in a short time, from a small sample, direct contact with participants, verifiable information and less costly.

\section{Analyses}

The following analyses are presented in an evolutionary approach starting from the early 80 s when the first cases of HIV/AIDS were diagnosed in Cameroon. The social changes that have occurred in this community within individual and collective lives have been traced and the changes that have influenced the life styles of the community members noted. According to the Social Dynamic Analyses theory, changes in any society could arise from the internal or internal forces. Social modifications being socio-cultural elements used to determine the influence of these biological phenomena in this community, the two biological phenomena (HIV and HBV) with close similarities but presenting great differences in their perceptions and representations will be compared. Their similarities lie in their etiology (virus), pathogenic form, main mode of transmission (sex intercourse), and chronic nature.

\section{From Late 80s to Early 90s}

HIV/AIDS was believed to be an illness of sorcery or witch craft and this belief was manifested through doubts, refusal of positive sero-status by infected persons and the entourage, accusations of witchcraft and sorcery. Classified among those health problems that cannot be diagnosed in the 'indigenous laboratories' (seers), there was the need for the intervention of some supernatural means. Patients suffering from this infection were classified as being attacked by some kind of evil spirit. HIV infected persons at that time could not be identified by any particular physical symptoms. The presence of this virus did not prevent infected persons from their daily functions including unprotected intimate or sexual activities. The rate of transmission became very high as infected persons continued to transmit the virus to their sexual partners ignorantly. The most serious victims were married women who according to this culture have as duty to satisfy their partner's sexual desires without hesitation.

During this same period, many people did not really believe that HIV was a reality. They doubted the truth behind this health problem and thought that, it was a means to disturb their sexual lives or better still, to promote the sales of condoms produced by the 'Whites'. This belief continued till about the early 90s. Although many people were losing close relations and friends as a result of HIV/AIDS, they still could not accept the cause of their death. They attributed to other reasons such as witchcraft or 'slow poison'. This widow who recounts her experience;

'When my husband was sick, we moved from hospital to hospital with him. The doctors said that he had HIVIAIDS, but we could not believe, we decided to take him to traditional healers to avail and he finally died. This was in 1991. After his burial, the doctor who was treating him called for me and advised me to do an HIV screening test. I did it and was diagnosed positive. This is when I started believing that HIV/AIDS really exist. Fear and shame made me to hide this from my in laws. I started living with this virus from that period till now with the help of an association that helped me morally, materially and at times financially through the payment of medical prescriptions and drugs".

The above experience is similar for many widows who are living with HIV infection today who accepted the reality about it only after the death of their husbands. This is because, they did not believe in the reality of HIV/AIDS until this virus killed their husbands. After the death of their husbands, they started to be conscious. It was observed that more than $80 \%$ of the widows who are being followed up at this hospital had lost their husbands from HIV/AIDS.

Around the early 90s, some people believed that HIV/AIDS was a 'slow poison'. This belief was developed as a result of the symptoms that surrounded most of those who were diagnosed of this virus. They had a gradual loss of weight as the disease progresses. This 
was comparable to some indigenous symptoms which indicated the presence of a poisonous substance in the body (most often described as spiritual poison/attack). When a person was diagnosed of a 'slow poison', it was believed that this poison destroys the body system gradually and most often leads to death. This patient recounted her experience;

During the time when HIV/AIDS started to gain grounds in Cameroon, many people thought that it was a 'slow poison' because the way that patients who were infected with this virus looked like was the same like persons suffering a 'slow poison'. Infected persons lost body weight gradually and finally died'.

More than $80 \%$ of our respondents declared that HIV is a 'killer disease'. This is a perception which translates the representation of the fatality of being infected with HIV. Death is the end product on anyone infected with this virus. They went further to support this with the fact that, it is a 'disease that has no cure' and so death awaits anyone infected with it. It is certain that everyone is called to die, but the cause and manner of death matters to the African man.

In the African cosmology, anything "Strange" is what cannot be recognized in the local or ecological milieu of the people. The nonexistence of endogenous, local or traditional treatment has pushed the population to bear in mind that, these are foreign elements in their culture.

In this context, where sickness is identified by the recognition of physical symptoms which are believed to be proper or originated from the living environment are sanctioned with a name. The naming of symptoms are being the first and most important element or aspects of ill-health recognition. It is in this same light that HIV and HBV are termed as "Strange diseases" because there is no local nomenclature for them. From investigations, all communities, social groups or clans in Cameroon have in one way or the other developed attributions to signify infections with HIV. There are stereotypic attributions which differ across the various cultural backgrounds and linguistic variations that identify labeling developed to symbolize persons infected with HIV or HBV.

Amongst the different beliefs surrounding HIV and $\mathrm{HBV}$ is the perception of a 'Foreign disease'. According to this perception, HIV is seen as a disease which came from out of the natural milieu of Cameroonians. This explains why this community has not accepted or is still to accept HIV and HBV as infections that their environment has not recognized. Acceptance or recognitions goes to agree with the 'disease theory' which is proper to the African health belief and practice system that stipulates the remedies for the management of diseases in that milieu.

\section{From Late 90s to Early 2000s}

By the Late 90s when this infection had gained grounds in the population of Cameroon and ravaged many souls, the hospitals wards were full with patients infected with HIV. The death rate was at its peak. Although a previous perception or belief had existed as stated above, there began to be changes in these perceptions and were manifested through fear and rejection towards infected persons (representing HIV to death). HIV/AIDS was still a 'killer disease' that killed mostly poor people. This was because the rich people could escape from such death due to their possession of the means to afford for Anti-retro-viral treatment (ART) in western countries such as France. ART was very expensive (about 1.500, 000 FRS per month). Only wealthy people infected with this virus could not be easily identified for the fact that, some of them flew to abroad for their treatment. Beside the ART that they took, they were able to maintain their health with food supplements that prevented the excessive weight loss. They were apparently healthy carriers of HIV and continued to carry out a normal sexual life without taking in to consideration any behavior change to avoid re-infection or the infection of their sexual partners. The 'slim syndrome' that became the prominent sign for the recognition for those suspected with this infection was well managed and served as a camouflage for their HIV positive status. This contributed to the continuous spread of this virus, they were those who have many sexual partners and pay well for their sexual services. More to that, people had started acquiring some knowledge on it from the sensitization campaigns that were organized by the disease control department of the ministry of public health that modified their health beliefs towards this virus.

The belief that HIV/AIDS was a 'killer disease' has persisted over these years despite the laborious health promotion campaigns that had been carried out by health care providers. More than $70 \%$ of our respondents confirmed that HIV had continued to kill despite the introduction of ART on the health market. At this period ART was already on the market but was still on sale as many Cameroonians who had HIV could not afford for these drugs that seemed expensive with respect to the average economic standard of Cameroonians. Many people were not yet on ART and thus continued to die as a result of this infection. There still was 'no cure' and so death awaits anyone infected with this infection. This patient narrates her story to confirm this;

"I was diagnosed to be HIV positive in 2005. This was during my Antenatal visits. I was in a total confusion because when I went back home, I heard many people were talking in the quarter that; HIV kills despite the ART that is given to infected persons. Any person infected with this virus most end up to die. Although the medical corps has been preaching that, people can put to birth healthy children (uninfected) if they are HIV positive, they do not believe in them because these children will end up dying. I was advised to go to 
the "Marabou" (traditional healers). It was said in these words; "vous perdez votre temps dans les ARV, parte chez les Marabou ».

Hearing about all these declarations I was ashamed to share my status to anyone, even during discussions on this topic, I pretended to be interested to hear what they think and are saying about this disease. I have never shared my HIV status to anyone even my boy-friend. I am afraid to tell my mother because she might die earlier due to the fear that she has concerning this disease. More to that, she has lost so many children, and knowing that I am HIV is sending her to an early grave". Since then, I was afraid and was left up with only one child who is 10years. I could no more make another child because we were counseled to always do protected sex. How then could I get pregnant when all sexual intercourse was protected?

Some people perceived HIV as a disease of the "Whiteman'. As history of HIV revealed that the first cases of persons diagnosed with HIV were from USA. Consequently many people believed that, USA is the country of the 'Whites' due to the domination of the 'White race'. Even though we know that, there are many 'Blacks' in USA. Africans and Cameroonians believed that, the 'White-man' was the first to be infected with HIV and therefore the disease is named after him. Knowing and acknowledging the sexual vulgarization, intravenous drugs consumption and homosexuality that is widely practiced amongst the 'Whites', HIV is said to have first infected these category of persons before reaching the heterosexuals. From the genesis, there exist great disparities in the perceptions through which these viruses arrived in Africa.

From the beginning of the HIV pandemic in Africa, most of those who were infected with this virus believed that, it was the end of their life in general and social life in particular. This was due to the sensitization messages that preached the adoption of positive behaviors for the maintenance of a healthy life and the protection of the social entourage. This consisted in the systematic use of condoms in all sexual activities, avoidance of blood contacts, screened blood transfusion, the non-manipulation of blood wetted objects.....etc. The drastic change to a new ways of life especially of sexual life was the most traumatizing issue where people were advised to reduce multiple sexual partners and stick to one partner whose HIV status is known. These advices seemed to be difficult to adopt making people consider it as the end of social life.

Some people confirmed that HIV is a 'bad sick' as compared to other chronic illnesses in general. This is as a result of the negative perceptions surrounding HIV making most people infected stigmatized. With regards to the negative attitudes that both health care providers and the patient's entourage had been giving to some patients living with HIV, some patients had decided to abandoned the hospital and wait for death at home because they are not able to bear the stigmatization. This patient narrates her experience;

When I was diagnosed of HIV in 2007, I was stressed up and decided to go and stay back at home to wait for death. This is because, the nurse who disclosed my results told me that "where you are now, it is only death; you will only die because nothing could be done to help you". I was afraid and also ashamed to disclose these results to neither my friends nor family members because they will reject me. I was not that type that goes out with many men, and could not believe how this happened to me. I suffered from a lot of rejection and stigmatization because, the father of my baby refused to do his own test and said that nothing existed like HIV. When I had opportunistic infections, he abandoned me and ran away that I had to die. Thank God that Religious people rescued my life and today I am still a life.

When ART were effectively introduced in the health care measures in Cameroon, the belief about HIV consistently changed. A greater proportion of the population thought that HIV/AIDS was 'curable'. This was because, most of those patients who were known to be infected with the virus and already presenting clinical signs such as; consistent weight loss, skin disease, TB, (opportunistic infections) could be seen to regain their clinical health. That is, gain a considerable weight to about or above the normal weight for those who had side effects of the ART drugs (fats deposits in some parts of the body such as the breast, stomach, buttocks, jaws.....). Others regained their skin color and became brighter than before. Those who had lost their hair started regaining their thick hair....etc. All these clinical signs that disappeared camouflaged the public, making some people to think that the main role of ART was not only the boosting of the body immune system but the weakening of the virus till it dies. Those on ART were prevented from rapid infection with opportunistic infections with the uses of other prophylaxis such as Bactrium.

In the late 90s and especially from 1996 marked another episode in the history of HIV and other chronic STIs such as HBV in Cameroon. During this is period, patients infected with HIV who were in their hidings for the lack of financial means to acquire ART had to come out of their hidings to the public view for the search of ART. At the same time, the first cases of HBV patients were being diagnosed in Cameroon, although the diagnoses test was still rare. Following the free grants for ART by the government, the perceptions towards HIV had to change. The belief was that HIV is a virus as the scientific medicine preaches. But the percentage of those who had this belief was less than $30 \%$. This showed that 
the knowledge on HIV was either not well understood or there was a mechanism of rejection of the knowledge that health care providers tried to impact on them. Only about $30 \%$ of our respondents were convinced that, they could still live with this virus with an apparent healthy situation if a good medical follow-up is done. This experience is share by one of our respondents in the following words;

"Since I was diagnosed of HIV/AIDS, I went and locked-up myself in the house for more than two years waiting to die to no avail. It is then that my elder brother discovered that I have abandoned every activity that I was doing and lost all hope in life. He approached me to inquire the problem and I tried to explain to him that I am HIV positive and have been waiting to die, but death was not soon coming. He then forced me to this hospital where I have come to be cared for".

People living with HIV usually develop opportunistic symptoms which are called AIDS. Most people have also taken this assumption in to consideration that HIV is AIDS (le VIH c'est le SIDA in the French speaking population) .There is this confusion between the virus (HIV) which causes the symptoms AIDS. This belief is held mostly by the category of people who are not highly educated. This is because; most educated people know that HIV is a virus which causes AIDS. Those who bear this belief have either have refused to understand the truth which is found in the sensitization packages or do not have the level of understanding to assimilate the good content of sensitization messages. HBV has no such perception from the public due to the ignorance of its existence.

\section{From Late 2000s Till Date}

In the government efforts to reduce the fear, shame, discrimination, and social stigma around HIV /AIDS, strategies were developed by health care providers to reduce the sigma by equating or better still comparing HIV/AIDS with other chronic illnesses. These messages did not take in to account the fact that other diseases can kill, can lead to severe loss of body weight, but there differ in their symptomatic manifestations. Their modes of transmission are not the same, their perceptions or health beliefs towards these illnesses also differ. Illnesses or diseases can be classified in to two major categories; acute diseases and chronic diseases. In comparing or equating HIV to other diseases, health care providers thought that, the stigma, shame, guilt, and rejection could be reduced. This approach was misunderstood in the sense that, many people have ignored or put behind other complications that could arise because of the chronic nature of these infections. These are problems such as; a constant or frequent medical visit or control, cost in consultations and laboratory exams, and at times the burden of constant drug consumption. This message has put the public in to more dangers than help because, most patients and their relations understood HIV in that light 'like any other disease', and without taking in to consideration it chronic nature and other therapeutic complications that can result from this infection (these are complications such as drug allergies, drug resistance, kidney failure and serious anemia). Even in it similarities to other chronic illnesses such as diabetes, cancer, hypertension and renal failure, HIV still makes a big difference in terms of other therapeutic challenges which come as a result of the resistance of the human body to some ART.

A poorly followed-up patient with HIV is likely going to face the problem of resistance to drugs (ART), whereas other chronic infections do not have the problem of resistance to drugs but may develop other implications due to their poor followed. About $40 \%$ of our informants declared that ' $H I V$ is an illness like others'. This category of patients used this declaration as a means to defend themselves from any sort of accusations from their social entourage. In the same order, other infections are either curable or controllable and thus have a minimum chance for therapeutic complications with respect to HIV or HBV treatment. HIV and HBV infections demand a life treatment for the moment.

Another perception of HIV is 'a Shameful disease' popularly called 'maladie dela honte'. The means through which it is transmitted remains a taboo in Africa. An infection whose main mode of transmission is through sex, remains a taboo in this context where sexuality is a hidden practice in this culture. Sexuality has a language which is translated through 'codes, signs or symbols' in many cultures and across all ages in Cameroon. In many age groups and social strata, especially the aged, sexuality is spoken in a silenced language. HIV is an infection which has come to break the silence and practice of this tradition. Exposing or disclosing your HIV status is exposing your transgression of the existing traditional norms. No one would therefore accept to be humiliated by his closed relations with a negative regard. This is not the same situation with HBV because, many patients and their relations are not only ignorant of the existence of this virus but also of it modes of transmission. Patients are therefore feeling relaxed or free to disclose their positive status without any fear of shame. This shows the disparity in terms of perceptions between these two infections which are similar in their pathogenic form, mode of transmission and chronicity.

Some people belief that HIV/AIDS is the 'End of social life with continuity'. This perception mostly emanates from that category of persons living with the virus, but who behind their positive sero-status have acquired other benefits that could not be possible if there were not living with this virus. These are patients who have joined social networks of persons living with this virus and through which they have obtained job opportunities that are 
providing them with a daily bread. In the UTHY we met with members of AFSO (Association des femmes' Solidaire) who have been in partnership with this institution for more than 10 years. Through their partnership with this hospital institution, they had undergone several training workshops to become psychosocial counselors to persons infected with HIV and HIV co-infections (TB, HBV, diabetes ...etc). Some of them had passed through NGOs that are involved in the fight against HIV to become data collectors for GTR (Groupe Regional Technique), CRA (Community Relay Agents), and presently called APS (Accompagnateur psychosocial).

These categories of person believe that HIV is an 'end of social life with continuity'. End of social life in the sense that, most of these women who are members of this association had an end in their social life at the moment when they were just diagnosed of HIV. Most of them are single (about 99\%) today due to the loss of their partners through death or separation. They have almost the same scenario with respect to the social responses that their immediate families and entourage gave to them when they were diagnosed HIV positive. The following are some of life experience;

It is when I lost my husband that I was diagnosed HIV positive. The doctor who took care of him called me later and advices me to do my HIV test. When I did it and it out to be positive, all my in-laws rejected me and my children',

The second person recounted the following;

'When I was sick of "Zona", my doctor asked of an HIV test which I did and it came out to be positive. When I released the results to my husband he refused neither to accept me nor to do his own test. I was driven away by my in-laws who said that 'their son could not have this type of illnesses. I have been living alone without a husband, but unfortunately my divorced husband almost died of recent because of AIDS. I hidden explained the situation to his doctor and asked that he should be tested. Unfortunately his test was positive. I did this because; I did not want the father of my children to die although we are not together. I do not mind living with HIV today, because, I have learned a lot about HIV and other opportunistic infections that have been empowered to be a bread winner and a renowned counselor' I have worked with in many projects because of my HIV status and is still working till date.

The third person narrated the following;

'When I was diagnosed of HIV in the 90s, I had one child and was pregnant with another child. But when the father of these children denied me due to my status, I had to abort the baby and up till date, I am left with only one child and could not find any serious man to accept me. But I am not regretting because, I have gained a lot from the association that I joined (AFSO) in those days. $I$ have undergone through many training workshops and today, I am a good counselor and also have an occupation that helps me to feed my child without stress.

Other patients' belief that HIV is God's way of spanking those who have disobeyed his rules as far as sexuality is concern or is a 'Divine punishment. These are mostly members of Pental Costal churches who believe that, there is no illness that God cannot heal. And if up till now, no perfect treatment has been found for HIV, it is a way of punishing sinners. They say that God is angry with the evil ways of man and as a result has decided to sanction them accordingly. According to this class of participants, sex was a secret and sacred act made by God for the purpose of procreation and not as an act of pleasure. Since man has decided to disobey this sacred instruction and turn to practice it for other ungodly purposes, God became angry and decided to inflict this illness (HIV/AIDS) to punish those who have gone against his commands. As such, this class of patients believes in divine healing from HIV if their sins are forgiven.

In the same way, others believe that HIV is a 'dangerous disease'. That is, a disease that puts the infected person to live a life of uncertainty. There is an uncertainty, because the infected person does not know what could become of him in the next future due to the non-assurance of the social repercussions of the illness or it development. He/she may be found in a situation of others who had died due to HIV despite the efforts made to save their lives, or may have a clinical good health like those who are presently living with the disease. This belief is held by almost $90 \%$ of those infected and affected with this virus. Most people perceive HBV as a yellow fever. This is due to some physical symptoms that appear at the secondary phase of HBV which consist of the yellowish of the eyes of the infected person. This is one of the symptoms that make many people to think that $\mathrm{HBV}$ is a chronic yellow fever.

\section{Discussion}

Many family setups have been destroyed due to the high level of deaths leaving many orphans, widows and widowers of HIV/AIDS. Clinical and therapeutic complications have influenced the social behavior of the infected and affected persons upsetting the emotional, social and sexual lives of persons living with it, making social life unbearable. Social behaviors have passed through the stages of doubt, rejection, fear, shame and guilt making the social history of HIV different from that of 
other chronic diseases. With respect to the level of sensitization that has been done on HIV, it is assumed that $95 \%$ of the population has at least heard of HIV in one way or the other. The government of Cameroon has done a lot in the domain of sensitization on HIV issues. The manner in which the information was transmitted seems to be problematic. At the level of it quality, the content of information has not been adapted with the context. One of the main reasons for sensitization is to induce positive behaviors and attitudes for positive change. That is to promote less risky so as to reduce new infections. But the results have been a very slow and consequently a constant rise in new infections.

This virus can infects anybody without distinction. There is the belief that HIV affects or infects mostly people with multiple sexual partners or people with a high sexual activity. Those who have stocked to one sexual partner are embarrassed with their positive HIV status because of this belief. In the same way, people who find themselves infected with HIV who have a low sexual activity (practice sex once in a month, three months or a year) have also doubted the source of their infection. Another category of persons estimate that HIV is a global issue and why border about changing behavior and attitudes toward this virus. HBV On the other hand is not as vulgar as HIV as the level of sensitizations made is still shallow. Many people are ignorant of this virus and at times believe in it only when a closed family member has been infected. It is therefore not perceived as a disease of the century as is the case of HIV. The sensitizations have created a sense of awareness towards HIV and the beliefs have changed from a 'Non reality' to 'a bad sick' for those who did not believe it existence. Today HIV is really a reality, but it modes of transmissions makes it to be believed as a 'Bad sick'. It exposes the private sexual life of people pushing them to be assumed as sexual deviants or promiscuous. For those who believed that HIV is a 'Slow poison', the belief has changed to 'Slim disease' as a way of explaining physical or clinical symptoms resulting from this infection.

HIV is also believed to be a 'Strange disease' and has evolved to the 'Disease of the White-man' because most innovations and research studies that talked on the clinical, biological and therapeutic evolutions have mostly been from the Western countries. The belief that HIV was a 'Foreign disease' multiplied to a 'Curable disease' when ART were introduced and clinical symptoms improved with patients who were on ART. More to that, ART is a foreign invention which is more valorized with respect to indigenous therapies that have been discovered in the course of the permanent research towards an effective cure for HIV. HIV is no more an illness of 'witch craft or sorcery' but an illness that leads to an 'end of social life' as numerous proscriptions are made for the adoption of a positive and less risky life.

According to the social dynamic theory, the perceptions and beliefs about HIV/AIDS have evolved over the years through the pressure from an external force that came from health care providers who kept on reinforcing sensitization strategies to change the perception of HIV by the population. An internal motivation to a change of perception came through those who were already on ART and noticed some clinical changes that motivated others to change their perceptions as presented above. This study has presented the social modifications that have occurred in this meso community as a result of the presence of HIV/AIDS and HBV. The main issues addressed in this study are the modifications of social lives caused by the nightmare of these chronic STIs. Health beliefs towards these infections being at the center of this social disarray have caused behavioral modifications that have taken place in the lives of persons living with these infections.

\section{Conclusions}

For over three decades that HIV/AIDS has existed in Cameroon, it is still making news and new stories amongst individuals and collectivities. The announcement of a sero-positive status still brings fear, shame, stigma and prejudgment as the newly infected and affected belief that sexual promiscuity is at its origin. The manifestation of shame and guilt has caused many to denial their status and therefore lead to the re-occurrence of co-infections with other STIs and sero-different partners becoming all sero-positive in the nearest future. It can be concluded that the present situation of HIV in Cameroon and Sub-Saharan Africa is as a result of the refusal to accept this new ailment and to adopt preventive measures that consist in applying less risky strategies across the different social and cultural strata. A new scene is arising from children born with this infection who have become adolescent and are at the school ages. These categories of persons living with HIV/AIDS are the most traumatized who often asked questions and blame their parents who may be late of their situation. The objective of this paper was to show how health beliefs towards these infections have produced social responses that have contributed to the present social modifications in the individual and collective lifestyles amongst persons living in this entourage. Health beliefs should be taken into consideration when treating health issues.

\section{List of Abbreviations}

STIs: Sexually transmitted infections

HIV: Human immune Virus

AIDS: Acquired Immune Deficiency Syndrome

HBV: Hepatitis B Virus

SSA: Sub-Saharan Africa

ART: Anti-retro-viral treatment 


\section{REFERENCES}

[1] Arnold, D. (1993). "Sexually transmitted disease in nineteenth and twentieth century India", Genitourinary Medicine, 69: 3-8.

[2] Berridge, V. \& Strong, P. (eds) (1993). AIDS and contemporary history, Cambridge: Cambridge University Press.

[3] Brandt, A.M. (1993). "Sexually transmitted diseases", in W.F. BYNUM and Roy PORTER (eds), Companion Encyclopedia of the history of medicine, London Routledge, Vol. 1: 562-584.

[4] Farmer, P.E. (1996a). "Social inequalities and emerging infectious diseases", Emerging Infectious Diseases, 2:259269.

[5] (1996b). "On suffering and structural violence: a view from below”, Doedalus, 125(1): 261-283.

[6] (1997). "AIDS and anthropologists: ten years later", Medical Anthropology Quarterly, 11(4): 516-525.

[7] Fee, E \& Fox, D.M. (eds) (1988). AIDS: the burdens of history, Berkeley: University of California Press.

[8] Nancy, R.H. (1994). STDs, Suffering, and their derivatives in Congo-Zaire: notes towards an historical ethnography of disease.

[9] Obbo, C. (1993a). "HIV transmission through social, and geographical networks in Uganda", Social Science and Medicine, 36(7): 949-955.

[10] (1997). "Normal social networking: unexamined patterns of migration and unexplored areas of HIV/STD transmission", Paper presented at the $\mathrm{X}^{\text {th }}$ International Conference on AIDS and STDs in Africa, Abidjan, December 1997.

[11] Oyekanmi,F.A.D. (1994b). “Women's attitudes towards sexually transmitted disease in Nigeria: a case study in Ilese in Osun state", Frica development, XIX (2): 147-165

[12] Reid, E. (1998). The ethics of disclosing as a strategy for social transformation, New York: UNDP. 